Specific Heats of Cobalt and Nickel. Pure fused. Cobalt S.G. $\frac{2 x^{\circ}}{4^{\circ}} 8 \cdot 718$
I0310
$\cdot$ I0378
I0310
$\cdot$ I0355
$\cdot$ I0373
$\cdot$ IO362
Arith. mean $\cdot 10348$ Atomic heat
Nickel S.G. $\frac{2 \mathrm{I}}{4^{\circ}} 8^{\circ} 790$

ro953
.10910
ro930
ro931
$?$

Further experiments will be made, because a single wellestablished case of this kind is sufficient to decide the question. Already, however, I feel certain that Kopp's conclusion is right, and that the law of Dulong and Petit, even for the metals, is an approximation only, and cannot be expressed in the words of the discoverers. For although the exact values of the atomic weights of these two elements are not known, it is certain that they are not so far apart as would be implied by these values for the specific heats, even assuming that the value for nickel is, as I believe, slightly too high.

Two other examples of somewhat similar kind are shown by gold and platinum, copper and iron.

Specific Heats of Gold and Platinum. Pure fused.

\begin{tabular}{c|c} 
Gold S.G. $\frac{18^{\circ}}{18^{\circ}} 19^{\circ} 227$ & Platinum S.G. $\frac{18^{\circ}}{18^{\circ}} 1^{\circ} \cdot 323$ \\
03052 & 03147 \\
03017 & 03150 \\
03035 & 03144 \\
Arith. mean 03035 & 03147 \\
Atomic heat 5.94 & 6.05
\end{tabular}

Specific Heats of Copper and Iron. Fused.

Copper (pure) S. G. $\frac{20^{\circ}}{20^{\circ}} 8^{\circ}{ }_{522}$
$\cdot 09248$
$\cdot 09241$
$\cdot 09205$
$\cdot 09234$
Arith. mean 09232

Atomic heat 5.83

$$
\begin{gathered}
\text { Iron S.G. } \frac{15^{\circ}}{15^{\circ}} 7745 \\
\text { Contains } 01 \% \mathrm{C} \text {. } \\
\text { II IO22 } \\
\text { II } 1037
\end{gathered}
$$

Arith. mean 11030 $6 \cdot 13$

For the gold I naturally applied to my colleague Prof. Roberts-Austen. The platinum I prepared from ordinary foil by re-solution, and reprecipitation as ammonic chloride, \&c. Both metals were fused into buttons before use. The atomic heats come closer together than those of cobalt and nickel.

Copper and iron differ considerably in melting-point, but both at the temperature of $100^{\circ}$ are far removed from even incipient fusion. The copper was prepared from pure sulphate by electrolysis, the iron by reduction of pure oxide in pure hydrogen. Notwithstanding all our care, it was disappointing to find it contained 'or per cent. of carbon, the source of which I am at a loss to explain. This iron is purer than any examined by Regnault or Kopp.

The differences observed between $\mathrm{Co}$ and $\mathrm{Ni}$, and between $\mathrm{Au}$ and $\mathrm{Pt}$, are manifestly not due to allotropy or to differences of melting-point, which in these cases can have no effect on the result.

So large a difference must be due to peculiarities inherent in the atoms themselves, and differences of atomic heat are to a certain extent comparable with the differences observed in other physical properties which, like specific volume, specific refraction, \&c., are approximately additive.

If we try to think what is going on in the interior of a mass of solid when it is heated, the work done is expended not only in setting the atoms into that kind of vibration which corresponds to rise of temperature-that is, it makes them hotter-but partly in separating the molecules or physical units from one another (= expansion), and partly in doing internal work of some kind, the nature of which is not known. A difference between metals and non-metals has been brought out by the researches of Heycock and Neville, who find that metals dissolved in metals are generally monatomic ; whereas it is generally admitted that iodine, sulphur and phosphorus in solution are polyatomic. It is, moreover, remarkable that although in respect to specific heat each element in a solid seems to be inde. pendent of the rest with which it is associated, when the separate

elements are dispersed in vapour some rise in separate atoms like mercury, some in groups of atoms $\mathrm{I}_{2}, \mathrm{~S}_{6}, \mathrm{As}_{4}, \mathrm{P}_{4}$, and these groups, as the temperature is raised, are simplified with very varying degrees of readiness.

Sulphur vapour, for example, diminishes in density from 7.9 at $468^{\circ}$, to 4.7 at $606^{\circ}$ (Biltz), that is, from about $S_{7}$ to $S_{4}$, and iodine from density 8.8 at $253^{\circ}$, to $5^{\circ} 6$ at $1570^{\circ}$ (V. Meyer), that is, from about $\mathrm{I}_{2}$ to $\frac{2}{3} \mathrm{I}_{2}$, but the dissociation of $\mathrm{As}_{4}$ and $\mathrm{P}_{4}$ begins only at much higher temperatures, while with mercury there is no corresponding change.

But, although these groups are taken as the chemical molecules, the physical unit in the solid is certainly the atom, whether united by combination or mere mixture.

The two metals, cobalt and nickel, with which I began my inquiry, have nearly the same atomic weight, but they differ from each other remarkably in chemical properties. For example, nickel forms a compound with carbonic oxide; on the other hand, cobalt produces many remarkable ammoniacal compounds, to which there is nothing corresponding among the compounds of nickel.

Having put aside the common excuses for the observed divergencies from the law of Dulong and Petit, we are compelled to look round for some other hypothesis.

The constitution of carbon compounds is now explained by a hypothesis concerning the configuration of the carbon atom introduced by Van t' Hoff and Le Bel twenty-five years ago, and which is now accepted by the whole chemical world. It seems not unreasonable to apply a similar hypothesis to the explanation of those cases of isomerism which have been observed in certain compounds of the metals, notably chromium, cobalt, and platinum. This has already been done by Prof. Werner of Ziirich. Of course, as there is no asymmetry, there are no optical differences in the pairs of compounds thus represented. If the constitution of compounds can be safely explained by such hypothesis, this implies peculiarities in the configuration of the indi. vidual constituent metals around which the various radicles are grouped in such compounds, and hence peculiarities in the behaviour of such metals in the elemental form may possibly be accounted for. For the atom of cobalt, Prof. Werner employs the figure of the regular octahedron. For nickel, therefore, which differs from cobalt, especially in yielding the remarkable carbonyl compound discovered by Mond, and by not yielding ammines like those of cobalt, and in other ways, a different figure must be chosen. This, however, is for the present a matter of pure speculation.

\section{SCIENCE IN THE THEATRE.}

[HE assimilation of nature on the stage! To what extent is assimilation possible, and what are the necessary methods and appliances for obtaining a satisfactory assimilation? This practically was the subject of a very valuable paper prepared for the Society of Arts by Mr. Edwin O. Sachs, the architect, which led to an animated discussion at the crowded meeting before which it was read. The title of Mr. Sachs' paper, it is true, was briefly "Stage Mechanism," but he went far beyond the mere description of the various appliances that can be used for obtaining certain scenic effects, and, more especially in his introduction, treated the subject on broad lines.

Though the presentation of drama and opera with some attempt at realistic surroundings is now accepted as a matter of course in all civilised countries, it can but rarely be said that the attempts are successful. In fact, only of recent years has the London manager been able to give us the presentation of indoor scenes with some claim to merit, and this only by building up his various scenes piecemeal in a most cumbersome way, which is all that is possible where the changes of scene are few and the "run" long. As to the presentation of scenes out of doors, the London manager has most lamentably failed, no matter how well painted individual canvases may have been, or how tricky the arrangements of individual scenic effects. A sky that looks like so much biue calico hanging on a wash-line, a horizon with angles, a tree that looks like a piece of cardboard, or a moon which suddenly rushes into the sky and then remains stationary, are all anomalies, and form only a few of the innumerable details which tend to make a scene incongruous.

Now according to Mr. Sachs, who fully recognises the attempts that have been made from time to time by Sir Henry Irving, Mr. Beerbohm Tree, Sir Augustus Harris, and others NO. I494, VOL. 58] 


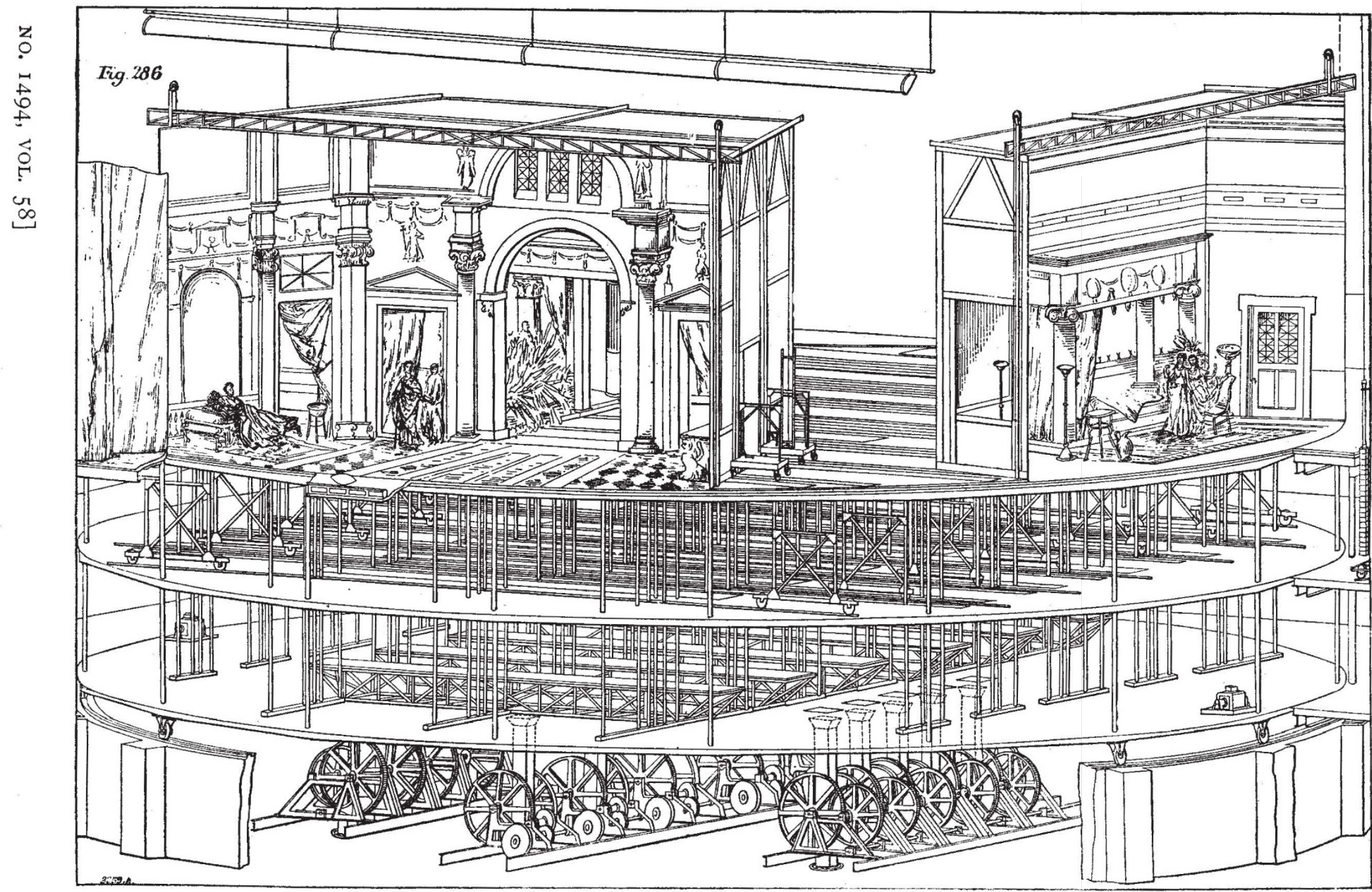

Fig. r.-Electric Turntable Stage. (From "Stage Construction.") 
(assisted by such eminent painters as Mr. Burne-Jones, or Mr. Alma Tadema), the reason for the anomalous scenes we see today is to be primarily found on the one side in the inherited prejudice of the stage against the adoption of anything that is new; and on the other, in that curious want of recognition which the stage fails to obtain, not only from the Government and public authorities generally, but from men of science who do not hesitate to use their knowledge for far more prosaic matters, such as, for instance, the tinning of food, the con. densing of milk, \&c. Mr. Sachs' assertions as regards the prejudice with which innovations are met with on the stage were amusingly confirmed in the discussion by Mr. Mulholland, who explained the difficulties he had in trying to do away with the tin-tea-tray thunder so often heard on our stages, and of course many curious anecdotes could be told of how the ignorant any spare five pounds. But there should be. Why not let the panorama scene cost ten pounds less and have the appliances?

Of course the average playgoer is not very critical; he is satisfied, as a rule, with the highly coloured picture and the blaze of light, and having been equally blind to the beauties of nature, sees nothing of the incongruities of the scene. $\mathrm{He}$ "sees" an actor with a streak of limelight following him round the stage, but does not grumble; he "sees" the actress, with her features distorted owing to a brilliant light from the footlights on her chin and a dark shadow on her forehead, but he does not know that there is anything wrong about this. Only that small percentage of playgoers who have visited some of the large model continental stages, or the Wagner productions at Bayreuth, perhaps appreciate the anomalies of the old Eng. lish stage, and scoff at what the caterers of our public enter-

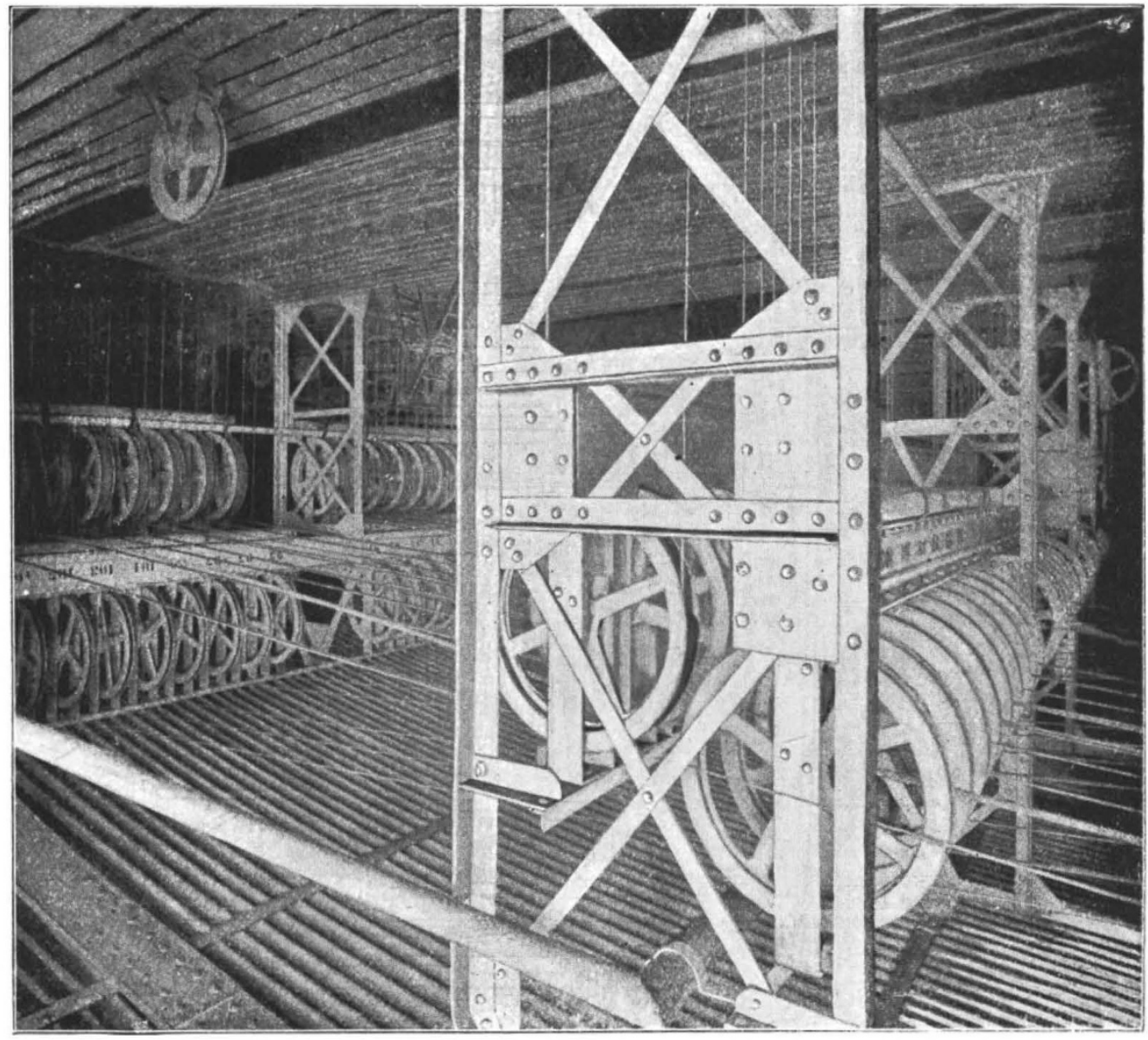

FIG. 2.-Court Theatre, Vienna. View of "Gridiron." (From "Modern Opera Houses and Theatres.")

stage-carpenter, or the stage-manager who is afraid of making experiments, or the prejudiced scenic artist who is afraid that improved effects might take away from his influence, all vie with one another in leaving the stage as it has been for a hundred years or more. Mr. Bernard Shaw also most wittily and scathingly showed how badly things are generally managed.

Now we cannot but recognise, as Mr. Sachs indicated, that much has been done in the way of painting good scenery. But what, as he said, is the use of the most beautifully painted piece of canvas if it is badly hung, wrongly lighted, and waves with every draught that there may be on the stage? What use is there, Mr. Sachs asked, in having a beautiful panorama scene, costing a thousand pounds, if the extra five pounds be grudged for a suitable appliance to make that panorama run smoothly? Mr. Moul, of the Alhambra, argued that there seldom were tainments choose to put before them. They know full well the harmonious effect often obtained on a well-managed continental stage, where the faults, if any, do not lie in the want of recognition of the true art requirements, but are to be found in the poor quality of the scenery, for the improvement of which there may not be funds available. How regrettable it is, as $\mathrm{Mr}$. Sachs pointed out, that we cannot have in the metropolis a happy combination of the artistic mounting of the Continent with the beautiful scenery for which our managers are ready to pay lavishly.

When, however, we go into the detail of Mr. Sachs' instructive paper, we find that the vast subject which he has covered does not lend itself to a short article of this description, nor perhaps would his arguments be appreciated without the many illustrations which he was able to put before his audience

NO. I 494 , VOL. 58 ] 
at the Society of Arts. Yet we would point out that, in the first place, he divided the stages he had under consideration into (1) wood stages, (2) wood-and-iron stages, and (3) iron stages; and that he then again subdivided them according to the power used for moving the scenery, or obtaining certain effects, be it manual labour, hydraulics, or electricity.

In speaking of the wood stage of the metropolis, Mrr. Sachs naturally does not omit to refer also to the wood stage of the Continent, which is but little better than our own; nor when he spoke of the wood and iron stage of Paris did he omit to speak of our "Palace" Theatre of Varieties, which is the solitary example of a theatre in this country in which a combination of wood and iron is to be found. When Mr. Sachs, however, came to speak of the iron stage, and more especially the iron stage worked by hydraulics or electricity, he had to confess that there was not a single iron stage to be found throughout the United Kingdom, that there was no stage worked by elcctric machinery, and that the only appliances in which hydraulics are being employed in this country were some so-called "bridges" at I)rury Lane. But on the continent, the iron stage, with all its improvements for lighting, for showing a curved horizon, and -to summarise-for giving some semblance of nature, is already to be found in considerable numbers and of considerable variety.

By Mr. Sachs's courtesy we are able to show two illustrationsone of the great electrical turntable stage for Munich, so useful for Shakespearean drama, where a quick change of scene is resirable, and the other of a hydraulic stage at Vienna worked on the suspended system. In the first case a general view is shown which well describes itself. In the latter case a view of the "gridiron" is shown, which plainly indicates the modern forms of wiring adopted.

But we cannot go further into the technical detail of the question, and we only trust that Mr. Sachs's words will have had some effect on the many managers and stage engineers who had come to hear him, not forgetting Herr Kranich, from Bayreuth, one of the leading exponents of scenic mounting on true art lines.

But whatever may have been the influence of Mr. Sachs's adrocacy, we would end by quoting him where he said "that the real secret of perfect scenic art lies in illusion, i.e. in visual leception, or in not allowing the eye of the spectator to discern the means whereby the semblance of reality is obtained; mere actuality will not accomplish this-crude realism alone would then result."

What the scenic artist and the stage-manager must attempt, according to Mr. Sachs, is to obtain a successful illusion; and this, he argues, is obtainable, not by any great ratical reform, as desired by irresponsible faddists, but a praitical reform of the methods and appliances which are to-day used on the stage of the metropolis, and which arc, unfortunately, quite a hundred years too old.

Why should not our stage have the full benefits of science and art as practised now on the approach of 1900 A.1)., instead of the makeshifts with which the world was satisfied at the heginning of the last century?

\section{UNIVERSITY AND EDUCATIONAL INTELLIGENCE.}

OXFORI. - Want of accommodation in more than one department of the Lniversity museum renders it impossible to carry on satisfactory work. The extracts printed below, from the report of the delegates of the museum, tell of a condition of "hope deferred, which maketh the heart sick." Prof. J. Burdon-Sanderson reports :- "The Regius Professor of Medicine takes this opportunity of expressing his bitter disappointment that another year has been allowed to pass without any step having been taken towards providing adequate accommodation for the teaching of medical science in the University. It is in his judgnent to be feared that if the reasonable requirements of the medical school continue to be disregarded, its further development will be checked, and that the progress of those departments of teaching which have common interests with it will be seriously interfered with." Prof. R. 13. Clifton, Professor of Experimental P'hilosophy, says : "Some electrical apparatus has been placed in the room formerly allotted to the professor as a private laboratory, and with that in the room devoted to the electrical work of the preliminary classes, it is now possible to offer some, though very NO. I 494, VOL. 58 ] restricted, facilities to Honour students who wish to grain experience in the methods of measuring electrical quantities. The professor and demonstrators have now, however, no place in which they can carry on research; and all attempts to undertake work of this character nust in future be abandoned. After twelve years of fruitless effort to obtain extended accommodation for Honour students, and the means of providing for the in creasing number of those working for the prelininary examination-a class of sturlents not contemplated when the laboratory was designed--it is probably quite useless to trouble the delegates with any further application for assistance in this direction." It will be difficult for men of science on the Continent and in the United States to believe that so little encouragement is given to scientific work in the University of Oxford.

The I9Ist meeting of the Junior Scientific Club was held in the physiological lecture-room of the museum on Friday, June 10. After private business, Mr. V. II. Veley, F.R.S., read a paper on Colcothrix methystes, the active microorganism which Mrs. Veley and himself recently discovered in "faulty" rum, and, it is hoped, will shortly form the subject of a monograph. After the paper a discussion took place, in which Dr. Ritchie and others joined.

CaMbringe--Mr. A. E. II. Love, F.R.s., of St. John's College, has been appointed University Lecturer in Mathematics in the room of Mr. Glazebrook, resigned.

The Senior Wrangler this year is Mr. R. IV. H. T. I Iudison, of St. John's College, son of Prof. W. II. H. Hudson, of King's Collegre, Loncton. Miss Cave-Browne-Cave, of Cirton, is bracketed fifth wrangler.

The Vice-Chancellor announces that donations anounting to over $6000 \%$. have been received for the University Benefaction Fund, started last year. A large number of the donations are ear-marked for the Medical School. A bequest of $10,000 l$. has also fallen to the University, but it is assigned to the foundation of a prize or scholarship in memory of the late 1)r. Allen, Bishop of Ely.

Mr. C. F. Hadfield, of Trinity, and Mr. R. C. Punnett, of Caius, have been nominated to the University tables at the Naples Zoological Station; and Prof. E. IV. MacBride, of St. John's, to the table at Plymouth.

The General Board propose that Mr. W. N. Shaw, F.R.S., should be appointed assistant-director of the Cavendish Laboratory for the ensuing year, in the place of Mr. Glazebrook.

I) R. R. A. IAARPER has been appointed professor of botany at the University of Wisconsin.

AT a meeting of the Court of Exlinburgh University on Monday a letter was read from a benefactor of the Lniversity, intimating that he is prepared to give to the University such a sum as may be necessary, but not exceeding $10, \mathrm{cool}$, to build and equip a laboratory and class-room to be used exclusively for the teaching of public health, the site of the proposed building to be provided by the University.

THE foundation-stone of a separate department for instruc. tion in the technology of the leather industries, was laid at the Yorshire College, Leeds, on Monday. The ceremony was performed by IIr. A. B. Kent, Warden of the Skinners' Company of London, who have provided $5000 \%$. in order to establish this department, and will contribute towards the working expenses.

THE new laboratories of physiology and pathology at the University College, Liverpool, will be formally opened on October 8. The laboratories have been erected and equipped in the most adequate way for study and research ly the Rev. Thompson Yates, at a cost of 25,000 . I ord I,ister, President of the Royal Society, has consented to perform the opening ceremony; and the Victoria University will take advantage of his visit to Liverpool to confer upon him the honorary degree of doctor of science.

AT the Science and Art Department on Friday last a conference was held of organising secretaries and other representa. tives of local organisations which have been recognised by the Department as responsible for science and art instruction within their several districts. The Vice-President of the Committee of Council on Education (Sir John Gorst) presided, and the conference was attended by representatives from a number of 